- RAM, REV. ADM. MACKENZIE, V. 11, N. 6, Edição Especial • SÃO PAULO, SP • NOV./DEZ. 2010 • ISSN 1678-6971 • Submissão: 13 mar. 2009. Aceitação: 17 abr. 2010. Sistema de avaliação: às cegas dupla (double blind review). UNIVERSIDADE PRESBITERIANA MACKENZIE. Walter Bataglia (Ed.), p. 31-54.

\title{
RELAÇÕES DE PODER E DECISÃO: CONFLITOS ENTRE MÉDICOS E ADMINISTRADORES
} HOSPITALARES

\section{POWER RELATIONS AND DECISION: CONFLICTS BETWEEN PHYSICIANS AND HOSPITAL MANAGERS}

\author{
LETÍCIA CORRỄA MAGALHÃES FERREIRA \\ Mestra em Administração pelo Programa de Pós-Graduação em Administração da \\ Faculdade Novos Horizontes (FNH). \\ Professora do Departamento de Administração do Centro Universitário \\ Metodista Isabela Hendrix. \\ Rua da Bahia, 2.020, Funcionários - Belo Horizonte - MG - Brasil - CEP 30160-012 \\ E-mail: leticiac@maisnet.com.br

\section{FERNANDO COUTINHO GARCIA} \\ Doutor em Ciência Política pelo Programa de Pós-Graduação em \\ Ciência Política da Universidade de São Paulo (USP). \\ Professor do Programa de Pós-Graduação em Administração da \\ Faculdade Novos Horizontes (FNH).
}

Rua Alvarenga Peixoto, 1.270, Santo Agostinho - Belo Horizonte - MG - Brasil - CEP 30180-121

E-mail: fernandocoutinho@unihorizontes.br

ADRIANE VIEIRA

Doutora em Administração pelo Departamento de Ciências Administrativas do

Centro de Pós-Graduação e Pesquisas em Administração da Universidade Federal de Minas Gerais (UFMG).

Professora adjunta da Escola de Enfermagem da

Universidade Federal de Minas Gerais (UFMG).

Rua Alvarenga Peixoto, 1.270, Santo Agostinho - Belo Horizonte - MG - Brasil - CEP 30180-121

E-mail: adriane.vieira@unihorizontes.br 


\section{RESUMO}

Os hospitais abrigam tensões de natureza grupal e profissional. Seu corpo diretivo e clínico é constituído por médicos que usualmente têm dificuldade de aceitar normas disciplinares e de ouvir recomendações, principalmente quando elas vêm dos administradores hospitalares. Esta pesquisa tem como objetivo analisar como administradores hospitalares da cidade de Belo Horizonte percebem as relações de poder entre sua categoria profissional e a dos médicos proprietários de hospitais e suas consequências. Os discursos de nove administradores hospitalares, com experiência mínima de quatro anos na gerência de hospitais, foram coletados e analisados usando a metodologia qualitativa. A pesquisa identificou que o hospital é um local da disciplina médica, no qual o médico controla o cotidiano dos demais profissionais, determinando o tipo de comportamento esperado. Os empregados entrevistados se ressentem da falta de autonomia na gestão e consideram que isso prejudica o andamento dos processos e a qualidade dos serviços prestados. Queixam-se, principalmente, da falta de informações e da impossibilidade de participarem das decisões estratégicas. Admitem que o relacionamento com os médicos proprietários é permeado por conflitos, pois, muitas vezes, estes ignoram as questões colocadas pelos administradores e insistem na diferença de classe como forma de fazer prevalecer suas opiniões. A principal característica dos conflitos refere-se à percepção de superioridade do profissional médico em relação aos demais.

\section{PALAVRAS-CHAVE}

Relações de poder; Hospitais; Conflito no processo decisório; Administração hospitalar; Médicos.

\section{ABSTRACT}

The hospitals hold tension originated from professional and group nature. Their directive and clinic bodies are composed by physicians who usually have difficult 
to accept discipline rules and to listen to the recommendations mainly when they come from the hospital managers. This research aims at analyzing how the hospital managers located in the city of Belo Horizonte perceive the power relations between their professional category and the doctors who own hospitals and their consequences. Nine speeches from hospital managers with at least four years of experience in hospital management were collected and analyzed through the qualitative methodology. The research identified that the hospital is a place of medical discipline in which the physicians control the daily operations of the other employees and determine the kind of behavior these employees should have. The employees who were interviewed resent the lack of autonomy to manage and they believe it harms the procedures and the quality of the services rendered. They complain mainly about the lack of information and the lack of possibility to take part in the strategic decisions. They admit that the relationship with the doctors who own the hospital is surrounded by conflicts because they usually ignore the issues brought up by the managers and insist on the social class difference as a way to make their opinions prevail. The main characteristic of the conflicts is about the superior perception from the physicians toward the other professionals.

\section{KEYWORDS}

Power relations; Hospitals; Conflict in the decision-making process; Hospital management; Physicians.

\section{INTRODUÇÃO}

A organização hospitalar apresenta estrutura orgânica extremamente complexa, na medida em que exige conhecimentos específicos necessários para gerir recursos físicos e humanos. Em épocas passadas, era administrada por curiosos, religiosos, militares e médicos que não tinham conhecimentos suficientes para geri-la. Nos dias atuais, segundo Cherubin (I999), ainda predomina uma administração pouco profissionalizada, executada por médicos proprietários, que, em sua maioria, não adquiriram conhecimentos necessários para tal e agem como se fossem profissionais especializados na área.

No entanto, pela lógica do mercado, sobrevive o hospital que produz melhores produtos, por meio de uma agressiva política de incorporação tecnológica e de um crescente aperfeiçoamento e controle de seus processos internos. 
Quem não se atualiza buscando novos avanços internos e não modernizando os processos de gestão termina ultrapassado pela onda de modernização, competitividade e eficiência marcante em nossos tempos (FEUERWERKER; CECÍLIO, 2007, p. 966).

Turner (I987, p. I57) afirma que “o hospital não é só uma instituição crucial nos sistemas de saúde modernos, mas simboliza também o poder social da profissão médica, representando a institucionalização dos conhecimentos médicos especializados".

Larson (I977) reforça tal concepção quando sugere que a extensão contemporânea da dominação médica entretece-se na história recente do hospital e que o impacto social crescente da tecnologia médica nas sociedades modernas resulta do poder social conferido à profissão médica, por meio dos hospitais e das universidades.

Nos hospitais ocorrem tensões de natureza grupal e profissional, assegura Gonçalvez (I998, p. 82), envolvendo o corpo clínico, constituído por médicos que trabalham no hospital, que têm muita dificuldade em "repartir seu poder, aceitar normas de disciplina coletiva e ouvir sugestões ou recomendações”. Contudo, mudanças se fazem necessárias nessas relações de poder entre corpo diretivo, clínico e técnico-administrativo, para que as organizações de saúde públicas e privadas promovam assistência segundo os padrões exigidos pela Organização Mundial de Saúde (OMS), pelos órgãos governamentais e pela demanda dos clientes.

Um exemplo da necessidade de imprimir às organizações hospitalares uma administração profissionalizada é a Portaria $n^{\circ} \cdot 2.225 / G M$, de 5 de dezembro de 2002, publicada pelo Ministério da Saúde (2007), na qual são estabelecidas exigências mínimas para a estruturação técnico-administrativa das direções dos hospitais vinculados ao Sistema Único de Saúde (SUS), como a contratação de profissionais com formação específica em Administração Hospitalar ou com cursos de qualificação na área, em função de seu porte (BRITO, 2004).

Conforme Carapinheiro (I998), a área de saúde apresenta escassez de estudos produzidos sobre as dimensões da gestão hospitalar mais estritamente ligadas aos fatores políticos, internos e externos, que bloqueiam seu exercício, ou, então, aquelas que se prendem ao enquadramento funcional.

Nesse contexto e visando preencher tal lacuna, esta pesquisa tem como objetivo analisar como administradores hospitalares da cidade de Belo Horizonte percebem as relações de poder entre sua categoria profissional e a dos médicos proprietários de hospitais. Para alcançar tal objetivo, foi realizada uma pesquisa 
do tipo qualitativo-descritiva em instituições hospitalares privadas, cuja diretoria clínica era composta por médicos proprietários.

Os sujeitos de pesquisa entrevistados foram nove administradores hospitalares, com experiência mínima de quatro anos de exercício da gerência em hospitais. A técnica de análise utilizada foi a análise de conteúdo do tipo categorialtemática. Na sequência deste trabalho, apresentam-se o referencial teórico que guiou a análise dos dados, detalhes sobre a condução da pesquisa e a descrição analítica dos dados.

\section{REFERENCIAL TEÓRICO}

\subsection{RELAÇÕES DE PODER}

O estudo do tema poder é, sem dúvida, um dos mais polêmicos e mais antigos, podendo ser encontrado nos primeiros escritos filosóficos de Platão e Aristóteles. A gênese de seu conceito está vinculada, mais propriamente, à filosofia e à ciência política, mas seu uso foi disseminado por todas as áreas das ciências humanas e sociais.

Para abordá-lo neste trabalho, vamos recorrer ao pensamento de Foucault, porque, como afirma May (2005, p. 65), apesar de haver se passado mais de vinte anos de sua morte, "podemos voltar a esse pensador, historiador e filósofo como se ele ainda falasse para nós, como se nós ainda não tivéssemos esgotado o significado de suas palavras".

Para autores da abordagem pós-moderna, como Foucault (2004), o poder não é um tipo particular de relações entre os indivíduos, pois não é uma substância. Ele não tem uma origem, uma fonte ou uma essência que o vincule ao Estado, à lei ou às instituições constituídas, portanto deve ser compreendido como uma multiplicidade de relações de forças imanentes ao domínio em que são exercidas; o jogo que, por meio de lutas e afrontamentos incessantes, transforma-as, reforça-as e as inverte.

Para Foucault (2003), identificar "quem tem o poder" não é importante; antes disso, é preciso estudá-lo no ponto em que se implantam e produzem seus efeitos reais. Nesse sentido, o autor se interessa principalmente pelos efeitos de verdade que o poder produz e como ele se legitima nas relações, criando discursos que funcionam como norma (FOUCAULT, I999).

Foucault (I979) define poder como uma relação de forças, ou melhor, para o autor, toda a relação de forças é uma relação de poder, podendo, então, conceber-se uma lista necessariamente aberta de ações que exprimem uma relação de forças 
ou de poder, constituindo ações sobre ações: incitar, induzir, desviar, tornar fácil ou difícil, ampliar ou limitar.

Foucault (2003, p. 7) compreende o poder "como não sendo uma instituição, nem uma estrutura, nem um poder estatal, mas um lugar estratégico onde se encontram as relações de forças".

Segundo Foucault (I979), qualquer agrupamento humano estará sempre permeado por relações de poder, uma vez que o pressuposto básico para a manifestação desse tipo de poder são as relações inerentes à vida social. É preciso levar em consideração que o fenômeno da dominação, com as diversas relações de poder que lhe são imanentes, antecede o próprio Estado.

\subsection{DISCIPLINA E CONTROLE DA ESPACIALIDADE}

Conforme Faria (I997, p. 30), "ainda que o poder não implique disciplina, há que se considerar o pressuposto da obediência ou do acatamento, seja por força de atos de imposição, seja em decorrência de interesses de cooperação".

A disciplina está ligada, segundo Foucault (I979), à docilização do corpo como objeto. O corpo que se manipula, molda, treina, obedece, responde e se torna hábil: a noção de "docilidade" que une ao corpo analisável o corpo manipulável. É dócil um corpo que pode ser submetido, que pode ser transformado e aperfeiçoado. Em qualquer sociedade, o corpo está preso no interior de poderes, que lhe impõem limitações, proibições ou obrigações. Não se trata de cuidar do corpo como se fosse uma unidade indissociável, mas de exercer sobre ele uma coerção sem folga, de manter nele, mesmo no nível da mecânica: movimentos, gestos, atitudes, rapidez. O corpo é o lugar privilegiado de investimentos e conformação dos gestos e dos comportamentos (GONÇALVES, 2007).

As características básicas do poder disciplinar, segundo Foucault (I979), são: a) a disciplina é um tipo de organização do espaço; b) a disciplina é um controle do tempo; c) a disciplina é uma vigilância contínua, perpétua, ilimitada; e d) a disciplina é o registro contínuo do conhecimento.

Para Foucault (I979), o exercício do poder disciplinar passa necessariamente pelas seguintes práticas sociais:

- enclausuramento: criação de um espaço "fechado" organizado em torno de regras e procedimentos que delimitam as ações cotidianas das pessoas;

- distribuição dos indivíduos no espaço e no tempo: cada indivíduo em seu lugar, e em cada lugar um indivíduo;

- hierarquização: as pessoas devem ser ordenadas de tal forma a promover a vigilância hierárquica. 
Destaca-se que as noções de espaço e geografia são centrais na obra de Foucault, uma vez que o que caracteriza o poder é a maneira como sua complexidade interna está associada às intervenções que se dão no lugar e no espaço (CRAMPTON; ELDEN, 2007). Todas essas práticas estão fortemente presentes nas organizações hospitalares, e é essa estruturação que permite a incorporação de práticas, hábitos e crenças (CAPPELLE; BRITO, 2002) que tendem a reforçar os mecanismos de alienação, submissão e apatia (ENRIQUEZ, I997). Portanto, denunciar o espaço organizacional como mecanismo de controle e dominação dos indivíduos implica denunciar o controle de seu olhar para atender a interesses de desempenho e lucratividade.

Os olhos dos indivíduos devem ser contidos no espaço que produz o excedente, de modo que nada possa interferir no processo de sua apropriação. Nesse pequeno mundo, começam a manifestar-se fortemente a territorialidade e a competição por espaços de sobrevivência (STAUB; BULGACOV, 2000), que, por sua vez, estimulam o aparecimento da agressividade e da violência, fazendo da empresa uma arena na qual indivíduos e grupos tentam obter posições de domínio, em função de seus interesses.

As partes mais fracas, oprimidas pela ordem, são, então, enclausuradas no espaço para que o controle sobre elas seja exercido de modo mais próximo, objetivo e direto. Os olhares fixam-se em linhas retas: linhas de montagem, linhas de produção, caixas empilhadas de produtos e pilhas de papel sobre as mesas. O espaço organizacional transforma-se, então, em espaço disciplinar: "cada indivíduo no seu lugar; e em cada lugar um indivíduo" (FOUCAULT, I987, p. I23).

A disposição de mesas e cadeiras, os quadros na parede, os vasos e os portaretratos sobre as mesas funcionam como demarcadores de território, evidenciando, desde logo, sua apropriação. Fischer (I994, p. 85) acrescenta que "esses demarcadores têm uma função preventiva, indicando aos outros quem possui e ocupa o espaço assim delimitado".

Essas demarcações podem também refletir e traduzir a posição ocupada por indivíduos na organização: as dimensões da sala ocupada, o andar ou local onde se localiza (geralmente, a alta direção ocupa os andares superiores - comando top down), o espaldar da cadeira (cargos importantes demandam cadeiras de espaldar alto), as dimensões (e estilo) da mesa; enfim, esses elementos estão impregnados de simbolismos de mensagens intra-ambientais. "A distribuição num espaço e a arrumação desse são uma expressão do sistema hierárquico e uma de suas formas mais visíveis" (FISCHER, I994, p. 9I). 


\subsection{O PODER MÉDICO E O SURGIMENTO DA CLÍNICA}

Até a Idade Média, o hospital não era considerado instituição médica, e a medicina não era uma prática hospitalar. Os hospitais medievais eram constituídos por um labirinto de pequenas celas minúsculas que comportavam apenas uma cama, em que circulavam os religiosos que traziam conforto espiritual aos doentes, constituindo-se como um local de assistência aos pobres e também de exclusão e separação social (ANTUNES, I989; ZAGONEL, I996).

Por volta de 1780 , a figura do pobre, que estava morrendo e precisava de assistência espiritual e material, foi substituída pela do doente que precisava de cura. A distribuição do espaço tornou-se um instrumento terapêutico, e o médico passou a ser o principal responsável pela organização hospitalar. A comunidade religiosa foi banida, para que o espaço pudesse ser medicamente organizado (FOUCAULT, 1994).

O primeiro fator que propiciou tal transformação foi a busca pela anulação dos efeitos negativos do hospital; assim, o foco deixou de ser o doente e sua doença. O segundo foi o desenvolvimento do conhecimento na área gerencial da saúde por parte de enfermeiras, médicos e outros profissionais (FOUCAULT, I994). Portanto, para que a experiência clínica surgisse como uma forma de conhecimento, o campo hospitalar foi reorganizado por meio de uma nova definição do estatuto do doente na sociedade e da instauração de uma relação entre a assistência e a experiência (ZAGONEL, I996).

Segundo Foucault (I994), surgiram, nessa época, as visitas e observações sistemáticas e comparadas dos hospitais e também o ritual religioso da visita aos pacientes pela equipe formada por médicos, enfermeiros, assistentes e alunos. Regulamentos em relação à visita aos leitos dos doentes foram criados, determinando o posicionamento de cada integrante da equipe. Estava criada a organização de um sistema que determinou o início da disciplina e da ordem na organização hospitalar, pautado por registros permanentes, procedimentos, normas, técnicas de atendimento, identificação, registro geral de entradas e saídas de doentes, visando à sua individualização, bem como à sua distribuição em um espaço em que pudesse ser vigiado.

Também no final do século XVIII, segundo Foucault (I979), surge a ideia de que o hospital deveria se constituir como um lugar propício ao estudo, à comparação de casos e como campo de estágio (residências médicas), ou seja, um estabelecimento educativo. Assim, ao longo da época clássica, a prática clínica foi se transformando com a reorganização dos hospitais como espaço clínico (ZAGONEL, I996).

No século XIX, a articulação entre anatomopatologia e a clínica no interior do hospital possibilitou a individualização de diversas doenças, a classificação de 
sintomas e o estabelecimento de vínculos, as lesões e a caracterização de uma ou outra doença (CAPONI, 2009).

No Brasil, a primeira escola para a formação de médicos e cirurgiões surgiu em I989, quando um grupo de médicos fundou no Rio de Janeiro a Sociedade de Medicina do Rio de Janeiro, "com o objetivo de tratar dos interesses médico-sociais e do ensino da Medicina, sob os auspícios do governo" (ZAGONEL, I996, p. 78).

A escola, segundo Berger e Luckmann (1985), funciona como um aparelho legitimador das funções sociais a serem assumidas, bem como da constituição das identidades profissionais. Ela é a encarregada de dar continuidade ao processo de socialização dos sujeitos, iniciado na família, permitindo a interiorização dos valores, das regras e das normas institucionais, cujo caráter e cuja extensão são determinados pela complexidade da divisão do trabalho e da distribuição social do conhecimento.

A linguagem, por sua vez, é o veículo de internalização dos esquemas motivacionais e interpretativos, que se refere a como ser um bom médico, respeitar a ética profissional, agir de acordo com os interesses da corporação, diferenciar-se dos demais profissionais etc. Portanto, além da linguagem, é preciso adquirir “compreensões tácitas, avaliações e colaborações afetivas desses campos semânticos" (BERGER; LUCKMANN, I985, p. I85).

Esse aparelho legitimador, que é a escola, é formado por professores médicos experientes, que se utilizam de símbolos, como o uniforme branco e a linguagem científica, e rituais compostos por exames e qualificações que garantem a aprendizagem de conhecimentos, habilidades e atitudes que caracterizam tal profissão e a diferenciam das demais, e ao mesmo tempo promovem a identificação subjetiva com a função e suas normas adequadas. Tal identificação é maior quando o status do conhecimento é elevado, bem como a valorização dessa atividade (BERGER; LUCKMANN, I985), como no caso dos médicos.

\subsection{CONTROLE, AUTONOMIA E CONFLITOS NA GESTÃO}

Conforme Cecílio (1997, I999), Alves, Brito e Penna (2007) e Alves et al. (2008), no microambiente das organizações hospitalares, encontram-se fatores que constituem a interação entre médicos proprietários e outras categorias profissionais, como enfermeiros e gestores hospitalares, os quais são imanentes à trama do poder instituída pelos primeiros, que colocam interesses individuais em disputa. Por ser esse um fato quase inevitável em qualquer ambiente de trabalho, é natural e compreensível a existência de tensões e de conflitos entre pessoas que trabalham no hospital. 
Apesar de a organização hospitalar não fugir do padrão comum das empresas da área da saúde, Cecílio (1997, I999) e Bernardes et al. (2007) analisam a forte resistência das corporações médicas e de enfermagem à implantação de um modelo de gestão mais descentralizado e com ênfase nas equipes.

Em uma avaliação sobre a implantação desse tipo de modelo de gestão da Fundação Hospitalar de Minas Gerais (Fhemig), situada em Belo Horizonte, foram levantados por Cecílio (I999) dois aspectos relevantes: a existência de conflitos entre o projeto da equipe e o projeto da instituição, evidenciando uma tensão entre a concepção de autonomia dos profissionais especialistas e das equipes; e os mecanismos de avaliação criados pela direção, vistos como controladoras, apesar de esta se orgulhar de estar trabalhando com um modelo de gestão democrático e com ênfase na autonomia.

Em um relatório de avaliação de quatro anos de implantação do modelo de gestão descentralizada e participativa no hospital São João Batista de Volta Redonda, Rio de Janeiro, Cecílio (I999) confirma as já conhecidas estratégias de não adesão dos médicos a qualquer modelo que tenha algum valor controlador. No trabalho realizado por Bernardes et al. (2007), em um hospital público do Estado do Rio de Janeiro, ficou evidenciado que, apesar da adoção de um modelo colegiado de gestão há quase dez anos, ainda há uma forte distância entre o discurso e a realidade vivenciada pelos trabalhadores, resultando em uma prática parcialmente colegiada, descentralizada e participativa.

O receio de perder poder para os administradores hospitalares pode impedir que os médicos visualizem a possibilidade de agregar novos conhecimentos para o crescimento institucional, correndo o risco de estagnar, muitas vezes, seu negócio durante longos períodos ou até mesmo levá-lo à desmaterialização.

Cecílio (1997, 1999) sugere que a autonomia dos médicos apoiaria as ações em comum se guiasse os gestores hospitalares para um futuro mais assertivo e comungasse com os interesses da organização sempre que fosse colocada em prática.

O poder legal deve e precisa ser utilizado para conduzir as ações com firmeza e objetivo, mas o despoder dos que são contratados para gerenciar as instituições hospitalares enfraquece o poder em comum. Luz (I986) sugere que a estrutura hierárquica se decompõe diante das várias faces dos desejos individuais, dos interesses que geram conflitos entre os proprietários e administradores responsáveis pela racionalidade da produção.

Vários autores, como Hall (I984), Lebrum (I984), Luz (I986) e Cecílio (I997), discutem a concepção de conflito de interesses. Dentre eles, Hall (I984) apresenta a ideia de que haveria três possíveis visões de conflito. A primeira encara o conflito como um fenômeno raro e transitório; a segunda, mais radical, entende o conflito como uma força motora onipresente e causadora de ruptura; e 
a terceira sugere que o conflito pode ser um aspecto reprimido do sistema social, nem sempre visível no nível empírico como uma realidade, aparecendo de forma silenciosa ou, como denomina Cecílio (I997), como o "não ruído".

De acordo com Luz (I986), as organizações formais e hierárquicas facilmente produzem atores autoritários, que são também profissionais interessados em organizar os serviços e a produção. Talvez não conscientemente os médicos tomem a direção de suas organizações para não perderem as rédeas de seus negócios, porém mudanças na estrutura organizacional e complexas informações na área de saúde podem situá-los em desvantagem competitiva no setor administrativo.

O fato é que, apesar da evolução das organizações hospitalares, elas ainda estão sujeitas ao poder dos médicos proprietários e ao seu controle sobre os administradores hospitalares. Dessa forma, a presente pesquisa busca o entendimento sobre as relações de poder que se estabelecem entre administradores hospitalares e médicos proprietários, bem como os possíveis conflitos existentes entre eles.

\section{METODOLOGIA}

A pesquisa realizada é do tipo qualitativa e tem como característica central o fato de o pesquisador procurar entender os fenômenos segundo a perspectiva dos atores sociais para, então, interpretar a realidade social. Assim, em vez de tratá-los como objetos passíveis de ser quantificados estatisticamente, dá-se voz a eles (BAUER; GASKELL; ALLUM, 2002).

Quanto aos fins, a pesquisa realizada é descritiva, pois expressa o desejo de conhecer determinado grupo, suas características e seus problemas, e exige que o pesquisador tenha o máximo de informações necessárias sobre aquilo que deseja pesquisar (GOULART, 2006).

O sujeito considerado para a execução da pesquisa foi o administrador hospitalar de instituições privadas da região metropolitana da cidade de Belo Horizonte, no Estado de Minas Gerais, constituídas por diretoria clínica formada por médicos proprietários. A escolha dos sujeitos obedeceu aos critérios de acessibilidade e a requisitos tais como: envolvimento no fenômeno, conhecimento amplo e detalhado das circunstâncias envolvidas na questão de pesquisa e experiência mínima de quatro anos de efetivo exercício gerencial na área hospitalar. Desse modo, foram entrevistados nove administradores hospitalares que atenderam aos referidos critérios, seis mulheres e três homens, todos com nível superior de instrução. 
As informações foram coletadas por meio de entrevistas individuais semiestruturadas. Assim, seguiu-se um roteiro que permitiu conservar certa padronização das perguntas, sem impor opções de respostas, permitindo ao entrevistado formular respostas pessoais que melhor expressassem sua subjetividade (VERGARA, 2003).

Todos os hospitais são sociedades anônimas, quatro são do tipo familiar, e dois não têm fins lucrativos. Todos eles contam com a participação de médicos no conselho administrativo ou na diretoria executiva. Quanto à forma de contratação dos administradores hospitalares, sete foram indicados para ocupar o cargo pelo Conselho de Administração, e os demais participaram de processos seletivos abertos.

Os dados foram analisados por meio da técnica de análise de conteúdo do tipo categorial-temática. Conforme sustenta Minayo (2000), a análise temática consiste em descobrir os núcleos de sentido que compõem uma comunicação cuja presença ou frequência signifique alguma coisa para o objeto analítico visado. Logo, fazer uma análise temática consiste em descobrir os temas, que são as unidades de registro nesse tipo de análise e que correspondem a uma regra para o recorte. Após o recorte, as unidades de significação foram classificadas e agregadas em categorias.

As principais categorias que nortearam a coleta e análise dos dados centraram-se nos fatores que envolvem os administradores hospitalares e os respectivos médicos proprietários, buscando investigar questões favoráveis ou desfavoráveis nas relações de poder, tipos de controle, disputa de interesses e tipos de conflitos.

\section{DESCRIÇÃO E ANÁLISE DOS DADOS}

\subsection{AUTONOMIA E PARTICIPAÇÃO}

Neste item, descrevem-se os poderes delegados pelos médicos proprietários aos administradores hospitalares e como estes participam da gestão.

No que se refere aos poderes delegados pelos médicos proprietários aos administradores hospitalares, há diferentes posicionamentos. Dos nove entrevistados, cinco se ressentem da falta de autonomia e afirmam que isso prejudica o andamento dos processos, bem como a qualidade dos serviços prestados.

Entre os administradores que se encontram insatisfeitos, a queixa principal se refere à falta de informações e à impossibilidade de participar das decisões que visam estabelecer diretrizes estratégicas. 
O administrador não é bem remunerado e também não participa de todas as decisões. Sua finalidade principal é responder às exigências e regulamentações do CRM. Faltam informações para podermos ajustar o planejamento e trabalhar com dados estatísticos que garantiriam a qualidade da assistência, efetividade, eficiência, aceitabilidade, legitimidade e equidade (Entrevistado I).

Existem assuntos ligados à diretoria clínica e outros assuntos que dizem apenas aos médicos proprietários que não são colocados para o administrador (Entrevistado 2).

Os poderes delegados estão relacionados apenas às decisões operacionais (Entrevistado 4).

Poderes para decisões operacionais que devem ser delegadas posteriormente por mim para os demais setores (Entrevistado 6).

Eu tomo apenas decisões que se aplicam às medidas operacionais (Entrevistado 7).

Nesses depoimentos, já foram encontrados elementos que permitem identificar o hospital como um local da disciplina médica, ou seja, aquele no qual o médico não somente cura os doentes, mas também controla o cotidiano dos demais profissionais, determinando o tipo de comportamento esperado (FOUCAULT, I979). Esse controle se dá, essencialmente, pela determinação de quem pode ter acesso às informações privilegiadas e a partir delas atuar, pois, como define Foucault (I979), o poder é uma relação de forças e, como tal, constitui-se por ações sobre ações, como: desviar, tornar fácil ou difícil, ampliar ou limitar. Assim, quando as decisões dos administradores hospitalares puderem, de alguma maneira, impedir que o interesse da classe médica seja sobrepujado, elas serão vetadas.

Na perspectiva foucaultiana, as relações de poder só podem ocorrer entre indivíduos livres que são capazes de resistir, de exercer forças contrárias. Caso falte liberdade, encontraremos relações de dominação (LUNARDI et al., 2007).

Dão os poderes necessários, porém, sempre que alguma atividade vai de encontro aos interesses pessoais, ela é desfeita. Os interesses deles se sobrepõem às obrigações da empresa (Entrevistado 8).

Conforme Luz (i986, p. I7), nas organizações hospitalares, é comum que o poder seja repassado com muita cautela, em um processo lento e com pouca confiabilidade por parte dos proprietários, denominados "generais sem exérci- 
to". Os administradores buscam a autonomia prometida pelo cargo e procuram desenvolver suas funções sem restrições. Porém, desde o início, suas ações estão limitadas e sofrem interferência frequente dos contratantes, que temem perder o poder nas relações, o poder autoritário, o poder da punição e o poder do controle, até então centralizado pela cúpula. No entanto, a qualidade dos serviços e a produtividade de uma organização, na contemporaneidade, estão intimamente relacionadas à rapidez das respostas às demandas do ambiente interno e externo, tornando a participação dos gestores e seus colaboradores nos processos decisórios elementos-chave do sucesso.

O administrador deve participar do sistema de uma empresa; para gerenciar é preciso unificar propósitos e produtos a fim de que todas as necessidades sejam satisfeitas: a do capital, a da sociedade, a do trabalhador e a do cliente (Entrevistado I).

O que poderia facilitar o trabalho do administrador seria reconhecer que existe este ambiente externo, que é competitivo e voraz, e suas influências. Deixar de ser familiar e passar a ser uma empresa de fato e não um grupo de amigos, como eles mesmos se rotulam (Entrevistado 8).

Nesses extratos de fala, existem coincidências em relação aos achados das pesquisas realizadas por Cecílio (I997, I999) e Cecílio e Moreira (2002), uma vez que revelam a expectativa de que os médicos partilhem as mesmas preocupações dos administradores quanto ao sucesso do negócio, comunguem dos mesmos objetivos, deleguem e concedam maior autonomia aos gestores, confiando em suas capacidades intelectuais, sem receio de perder o poder.

Luz (I986) sugere que a acentuada autonomia dos médicos, defensores de regras e normas profissionais na rotina administrativa, em contraposição à necessidade de uma gestão eficaz por parte dos administradores contratados, mesmo nos modelos mais participativos e democráticos, tem demonstrado resistência por parte dos colaboradores, denunciando seu caráter autoritário. Portanto, os atributos de rigidez, autoritarismo e coordenação inadequada que têm caracterizado os serviços de saúde provêm mais da organização profissional do que de suas características burocráticas.

\subsection{RELACIONAMENTO DOS MÉDICOS PROPRIETÁRIOS COM O ADMINISTRADOR HOSPITALAR}

O tipo de gestão, no que se refere ao poder e à autonomia delegados, é consequência e, ao mesmo tempo, reflexo da qualidade do relacionamento que se 
estabelece entre os médicos e os demais profissionais que atuam no espaço hospitalar, além do respeito às diferenças resultantes dos distintos papéis a serem desempenhados, que, por sua vez, englobam diferentes atribuições e responsabilidades (CECÍLIO, I997; ALVES; BRITO; PENNA, 2007; ALVES et al., 2008).

Nos casos estudados, no entanto, há divergências de opinião quanto a essa questão. Cinco entrevistados afirmam que os relacionamentos são permeados por respeito mútuo e cordialidade.

De forma cordial e intensamente (Entrevistado 2).

Há respeito mútuo (Entrevistado 3).

Sem problemas (Entrevistado 5).

Bom relacionamento, sem problemas. Divergências normais do dia a dia (Entrevistado 7).

Em perfeita sintonia de relacionamento e respeitabilidade (Entrevistado 9).

Dois entrevistados reconhecem que há diferentes posturas entre os médicos; alguns "ouvem as opiniões dos administradores", enquanto outros "ignoram as questões colocadas pelo administrador" (Entrevistado 4) e "buscam na diferença de classe formas de fazer prevalecer as suas opiniões" (Entrevistado 6). Dois outros foram ainda mais veementes em suas críticas.

Existe pouca parceira entre médicos e administradores. Vivem em constantes conflitos. Alguns médicos até se relacionam bem com os administradores, mas só quando há troca de benefícios. Outros esquecem até da administração e valorizam apenas a classe médica. Os que não se adequaram a essa política já saíram da instituição (Entrevistado I).

Eles não identificam o administrador como o profissional que gerencia o seu negócio, mas sim como o seu secretário, para atender suas necessidades pessoais. Há mistura de obrigações e rotinas da empresa com os afazeres pessoais médicos (Entrevistado 2).

A explicação para a existência de conflitos nos relacionamentos, segundo os entrevistados, está na presença de disputa de interesses entre a classe médica e os administradores, que, muitas vezes, possuem objetivos diferentes. Mais uma vez, apontam-se aqui semelhanças com os achados das pesquisas de Cecílio (1997, 1999) e Bernardes et al. (2007), quando estes abordam a presença das tramas de poder institucional pelos médicos ao colocar seus interesses pessoais em disputa. 
Cinco entrevistados afirmam que os objetivos dos médicos proprietários entram em conflito com os objetivos organizacionais, pois os primeiros tendem a priorizar seus próprios interesses, sobrepondo-os aos da organização.

O poder é de fácil acesso para os médicos, desde a universidade. Eles adoram se manter no pedestal, distantes, superiores às outras classes. Deixam bem claro que quem cursa io ou in anos de faculdade, pesquisando o ser humano, sabe muito mais que as outras classes. Não são de discutir com os outros, dão ordens que devem ser acatadas (Entrevistado I).

O administrador e os médicos proprietários têm pensamentos diferentes, visões diferentes. Além disso, são vários proprietários, cada um com opiniões diversas, e muitas vezes esse fator gera conflitos (Entrevistado 2).

$\mathrm{Na}$ instituição privada, sem fins lucrativos, às vezes os objetivos do médico administrador entram um pouco em conflito com os da instituição. Ele (o médico) se preocupa com o seu objetivo, com os seus interesses, visto que é um personagem passageiro naquela instituição (Entrevistado 4).

Os médicos tentam valorizar seus interesses acima da organização (Entrevistado 5).

Nós temos problemas com os planos de saúde, que nem sempre pagam para o paciente a melhor tecnologia. Esse fato irrita profundamente o corpo clínico. O conflito existe quando o administrador hospitalar não consegue o melhor material cirúrgico; equipamentos a serem pagos pelos planos de saúde (Entrevistado 6).

Eles transmitem literalmente através da fala: - eu sou dono (Entrevistado 9).

A principal característica dos conflitos expostos refere-se à percepção de superioridade do profissional médico em relação aos demais, ou seja, aos "outros" que não fazem parte da mesma categoria profissional e/ou classe social. Essa percepção, muitas vezes, é gerada pelos aparelhos legitimadores, como as instituições de ensino, em que professores, durante o processo de socialização dos alunos, utilizam-se do discurso e de recursos simbólicos para interiorizar valores e normas que os diferenciam dos demais e, ao mesmo tempo, fazem-nos acreditar que seu mundo é o único e o verdadeiro mundo que existe.

Nesse sentido, a interiorização se constitui como a base da compreensão de nossos semelhantes, e a socialização é o processo de introdução de um indivíduo no mundo objetivo de uma sociedade ou de um setor dela (BERGER; LUCKMANN, I985). 
Um elemento importante do processo de socialização são os "outros significativos", ou seja, os professores e médicos, pois são eles os mediadores que se encarregam da socialização. Segundo Sainsaulieu (I977), a disputa pelo reconhecimento social é sempre uma experiência conflituosa, pois de um lado está o sujeito, buscando expressar seus desejos e se apropriar de objetos, e de outro está a estrutura social, composta por outros sujeitos com desejos, que, na maior parte das vezes, concorrem com os seus.

Para Foucault (2003), é mais importante estudar a produção dos efeitos reais do poder do que identificar quem tem o poder. Ou seja, é preciso identificar os efeitos que o poder produz e como ele se legitima nas relações, criando discursos que funcionam como norma (FOUCAULT, I999). Ainda de acordo com o autor, o exercício de tal poder está pautado na disciplina e no conhecimento/ saber como objetos desse controle, pois é a partir dele que os indivíduos passam de condutores a repetidores enquadrados em disciplinas.

Um dos entrevistados consegue apontar outro ator envolvido na disputa de interesses com os administradores, além dos médicos, que são os enfermeiros, pois, "do ponto de vista da cultura organizacional, a enfermagem está mais próxima dos médicos" (Entrevista 7 ).

O objeto mais evidente da disputa, de acordo com um dos depoimentos, refere-se à compra e à utilização de materiais e equipamentos de tecnologia avançada, para que os médicos possam realizar seus diagnósticos e tratamentos com qualidade e também protegê-los de reclamações. Nesse ponto, os administradores argumentam que as despesas dependem de receitas e que os investimentos devem acontecer também em outras áreas, como hotelaria, recepção, transporte, redimensionamento de espaços, segurança, serviço de nutrição e dietética (SND), que são de responsabilidade do administrador, mas não são prioridade para os médicos.

É nesse momento que os administradores sentem o peso da superioridade médica no processo de tomada de decisão. Os entrevistados foram unânimes em afirmar que o nível de influência dos médicos no processo é elevado e que, em situação de disputa de poder, eles ignoram os administradores e recorrem ao corpo diretivo do hospital, que costuma ceder às suas pressões.

Eles influenciam utilizando o poder de conhecimento sobre a medicina e sobre a necessidade dos nossos clientes (Entrevistado I).

Quando há divergência de ideias, eles se sobrepõem à ideia do administrador hospitalar. Influenciam diretamente, não permitindo que nenhuma decisão seja tomada sem o consentimento deles. Alguns determinam, por exemplo, quais marcas de produtos médicos podem ser utilizadas (Entrevistado 2). 
Nenhuma decisão é tomada sem o consentimento deles e do corpo religioso. Eles resistem centralizando todas as decisões. Determinam inclusive com quais materiais e equipamentos se sujeitam a trabalhar (Entrevistado 6).

Gerentes são indicados pelos médicos e se reportam a eles. Eles tomam todas as decisões estratégicas. Por ser uma diretoria com membros acima dos 70 anos, é conservadora. Isso prejudica a agilidade de tomada de decisão e maior agressividade das ações (Entrevistado 7).

Crescer gera trabalho, gera compromisso, gera dedicação. A organização foi criada apenas para gerar emprego para eles, logo, basta ela apenas existir (sobreviver) que já lhes atende. Sim, basta lembrar o jargão muito citado: médico acha que é Deus, mas alguns têm a certeza! (Entrevistado 8).

Resistem acionando o corpo diretivo da instituição. A maior resistência é quando são acionados a fazerem aportes de capital para ajudar na sobrevivência da instituição (Entrevistado 9).

Analisando os extratos das falas, é importante destacar que, quando se perguntou aos administradores como os médicos influenciam a tomada de decisão e se/como demonstram sua superioridade, todos os entrevistados se manifestaram revelando os antagonismos nos relacionamentos, mesmo aqueles que, em momentos anteriores, se disseram satisfeitos com a qualidade dos relacionamentos e com liberdade e autonomia para a ação.

Nesse ponto, chamamos a atenção para a presença de conflitos reprimidos, que aparecem de forma silenciosa, conforme Hall (I984), ou sem ruídos, segundo Cecílio (I997). Podem ser considerados também conflitos latentes, no sentido de que há um conflito de desejos e preferências entre aqueles que exercem o poder e aqueles sujeitos a ele, uma vez que estes têm consciência de seus interesses.

\subsection{CONFLITOS, PREJUÍZOS E SOLUÇÕES}

Neste item, apresenta-se a percepção dos entrevistados sobre as implicações de um tipo específico de conflito, aquele gerado por ações por parte dos médicos que visam prejudicar a credibilidade do administrador ao desautorizar suas decisões. Examinam-se, também, os prejuízos emocionais e organizacionais desse tipo de comportamento.

Dos nove entrevistados, somente três afirmaram que nunca foram desautorizados pelos médicos proprietários e pelas gerências intermediárias, o restante informou que isso já acontecera. As reações deles a tal ato variam. Existem aqueles que entendem que nem sempre suas decisões são as mais adequadas e devem mesmo ser contestadas, e aqueles que afirmam que isso gera desgaste 
emocional, perda de produtividade e de comprometimento de toda a equipe, com enfraquecimento do papel dos administradores e aumento da insegurança para tomar a decisão certa na próxima ocasião.

Sim, desautorizam às vezes, porém de forma conveniente. Não incomoda, pois são medidas necessárias e coerentes. Não prejudica, agrega (Entrevistado 5).

Não me incomoda muito, pois nem o tudo que é proposto deve ser aprovado (Entrevistado 7).

Gera descredibilidade entre os colaboradores e me deixa insegura para tomar a decisão certa na próxima vez. Nunca se sabe se terei que voltar atrás nas minhas decisões (Entrevistado I).

Eu me sinto muito incomodado quando chego perante a equipe de trabalho e percebo que o trabalho está sendo desenvolvido de outra forma porque o proprietário decidiu assim (Entrevistado 4).

Isto me incomoda. Prejudica sensivelmente a gestão. Gera retrabalho, horas extras, desgaste psicológico, perda de comprometimento dos colaboradores etc. (Entrevistado 8).

Não diretamente, pois, quando querem atuar em benefício próprio, procuram colaboradores com pouca informação na busca de apoio. Mas isso gera descredibilidade em relação à minha tomada de decisão e diminui o senso de equipe dentro da organização (Entrevistado 9).

Essa é apenas mais uma faceta da disputa pelo poder entre classes profissionais, classificada por Luz (I986) como o "despoder" daqueles que são contratados para gerenciar. Conforme a autora, isso acaba enfraquecendo o poder comum, uma vez que a estrutura hierárquica se decompõe diante das várias faces dos desejos individuais, gerando desconforto para aqueles que são responsáveis pela racionalidade dos processos, isto é, para os administradores hospitalares.

Se a instituição está indo bem ou não, o problema é da administração e não dos médicos. Poucos médicos se envolvem com todos os interesses da organização, e ainda tem alguns médicos que, por não suportarem tanta pressão ou o tipo de política interna, pedem demissão (Entrevistado r).

Poderíamos ter uma maior participação dos médicos nas negociações junto aos planos de saúde, no intuito de tentar orientar, convencer os responsáveis pelos pacotes a praticarem melhores preços e permitirem o uso de melhores materiais nos kits (Entrevistado 6). 
A fala do entrevistado I remete às considerações de Luz (i986) de que, muitas vezes, os médicos mostram-se omissos quando optam por manterem-se à distância do processo gerencial, declarando uma posição centralizadora onipotente.

Por sua vez, a fala do entrevistado 6 nos remete à consideração de que a condição de médico e de proprietário é, por si só, conflitante. Defender os interesses da organização em vez dos de classe é uma dura decisão a ser tomada, uma vez que muitos deles são beneficiados pelos planos aos receberem pagamento pelos serviços prestados e têm a expectativa de serem bem remunerados por suas consultas e seus procedimentos, e, ao que tudo indica, os interesses de classe têm sido priorizados.

Quando questionados sobre a consciência dos médicos quanto ao conflito por eles gerados e sobre como buscam soluções para tal, seis dos entrevistados mencionaram que eles têm ciência; dois afirmaram que não; e um ponderou que às vezes. Sobre a forma como buscam resolver os conflitos, os entrevistados foram categóricos ao afirmarem que isso faz parte das relações de poder na organização, que os médicos não se mobilizam para encontrar uma solução e que, nessas situações, delegam para os administradores a responsabilidade por encontrar uma solução; mais uma vez reforçando uma omissão conveniente.

\section{CONSIDERAÇÕES FINAIS}

Os hospitais apresentam uma estrutura hierarquizada que abriga diferentes e às vezes conflitantes interesses das categorias profissionais, que devem ser equacionados no cotidiano do trabalho. Os cargos de direção são geralmente ocupados por médicos do sexo masculino, que se ocupam das decisões estratégicas, enquanto as demais categorias profissionais se encarregam da operacionalização dessas decisões, como os administradores hospitalares.

No passado, os hospitais eram administrados por religiosos e militares; nos dias atuais, apesar de ainda predominar uma administração executada por médicos proprietários, já existe uma exigência de profissionalização da gestão, ditada pela lógica da competição de mercado, de incorporação tecnológica e do aperfeiçoamento do controle dos processos internos.

Nesse contexto, a pesquisa realizada teve como objetivo analisar como os administradores hospitalares da cidade de Belo Horizonte percebem as relações de poder entre sua categoria profissional e a dos médicos proprietários de hospitais. Usando a metodologia qualitativa, foram coletados, descritos e analisados os discursos de nove administradores hospitalares, com experiência mínima de quatro anos de exercício da gerência em hospitais. 
Os dados permitiram identificar o hospital como um local da disciplina médica, no qual o médico controla o cotidiano dos demais profissionais, determinando o tipo de comportamento esperado. Tal controle se dá pela determinação de quem pode ter acesso às informações privilegiadas e, a partir delas, atuar (FOUCAULT, I979).

Os administradores hospitalares entrevistados se ressentem da falta de autonomia na gestão e consideram que isso prejudica o andamento dos processos, bem como a qualidade dos serviços prestados. Queixam-se, principalmente, da falta de informações e da impossibilidade de participarem das decisões estratégicas. Também revelam a expectativa de que os médicos partilhem das mesmas preocupações, no que se refere ao sucesso do negócio, que deleguem, confiando em suas capacidades técnicas, e que comunguem dos mesmos objetivos organizacionais.

Os entrevistados admitem que o relacionamento com os médicos proprietários é permeado por conflitos, pois, muitas vezes, estes ignoram as questões levantadas pelos administradores e insistem na diferença de classe, utilizando-a como forma de fazer prevalecer suas opiniões. A principal característica dos conflitos refere-se, portanto, à percepção de superioridade do profissional médico em relação aos demais.

Outro achado da pesquisa refere-se à presença de conflitos reprimidos e latentes, no sentido de que há consciência das divergências de desejos e de preferências entre aqueles que exercem o poder e os que são sujeitos a ele. Esse conflito é resultado, principalmente, de um tipo específico de ação, por parte dos médicos, que prejudica a credibilidade do administrador ao desautorizar suas decisões, levando ao desgaste emocional, à perda de produtividade e de comprometimento de toda a equipe e ao aumento da insegurança para a tomada da decisão.

Os resultados desta pesquisa reforçam os achados dos estudos de Luz (I986), Cecílio (1997), Cecílio e Moreira (2002), Carapinheiro (1998), Cherubin (1999), Feuerwerker e Cecílio (2007) e Bernardes et al. (2007), ao revelar que, na relação entre médicos e demais grupos profissionais, ainda prevalecem práticas autoritárias, as quais não permitem que as decisões sejam tomadas pelo grupo de trabalho. Isso indica que o modelo tradicional de gestão permanece fortemente introjetado no imaginário e nas práticas sociais brasileiras, mesmo quando há um discurso de participação.

Não significa dizer que não haja avanços, no entanto as mudanças se dão de forma lenta e gradual, pois a resistência é um traço da natureza humana, e o paradigma hegemônico da prática médica, ao que tudo indica, não será superado facilmente, principalmente quando se trata de criar novas formas de gerenciamento, com base no compartilhamento de responsabilidades e decisões. 
É importante lembrar que o processo de redemocratização da sociedade brasileira se iniciou no final dos anos ig80 e que ainda permanecem no poder representantes das gerações que sofreram influência de processos de socialização do período ditatorial. A classe médica detém prestígio e goza de mais status que outras com as quais convive no espaço hospitalar; reverter esse quadro implica mudanças de valores e também fortalecimento dos órgãos de representação dessas categorias profissionais, como os conselhos profissionais, que devem defender os interesses do coletivo, exercer a fiscalização ética e técnica e promover o debate, buscando melhorias para a profissão.

Por fim, os resultados da pesquisa indicam que não é mais possível manter a velha forma de organização, na qual atuam em paralelo um sistema administrativo e um assistencial, pois o controle financeiro de uma organização depende da racionalização do emprego de recursos no atendimento aos pacientes. Delegar aos administradores hospitalares autonomia nas tomadas de decisão é uma forma de garantir não apenas a sobrevivência, mas também a perpetuação bemsucedida dos negócios. As formas de controle são inerentes à administração, mas, se utilizadas para a manutenção dos interesses da organização, podem trazer benefícios na construção de uma nova estrutura organizacional, que foque seus trabalhadores e, principalmente, a produtividade deles em equipe. O desafio é a implantação de um modelo gerencial que promova a distribuição mais homogênea do poder, pautado no diálogo.

Os médicos, em seu trabalho, fazem a diferença, porém a maneira como os administradores trabalham com esses profissionais poderia resultar em uma vantagem competitiva. Assim, espera-se que este estudo contribua para que médicos e administradores hospitalares se conscientizem acerca de seus diferentes papéis, colaborando de modo efetivo para o aumento da produtividade e do aperfeiçoamento da qualidade dos serviços prestados pela organização hospitalar à comunidade que servem.

Sugere-se que outras pesquisas sejam realizadas, visando ao aprofundamento do entendimento dessa situação de conflito entre médicos e administradores hospitalares, levando em consideração também a interferência de outras variáveis como gênero nos estudos sobre gerência e as diferenças intergeracionais de percepção do papel e das práticas dessas categorias profissionais.

\section{REFERÊNCIAS}

ALVES, M.; BRITO, M. J. M; PENNA, C. M. M. Identificación de los gerentes com su trabajo em unidades básicas de salud de Belo Horizonte: realidad o utopia? Enfermería Global, Murcia, v. II, n. 2, p. I-I4, nov. 2007. 
ALVES, M. et al. Práticas de gestão, relações de poder e de gênero na organização hospitalar. In: ENCONTRO DE ESTUDOS ORGANIZACIONAIS DA ANPAD, 5., 2008, Belo Horizonte. Anais... Rio de Janeiro: Anpad, 2008.

ANTUNES, J. L. F. Por uma geografia hospitalar. Tempo Social, Revista de Sociologia, São Paulo, v. I, n. I, p. 227-234, I989.

BAUER, M. W.; GASKELL, S.; ALLUM, N. C. (Org.). Pesquisa qualitativa com texto, imagem e som: um manual prático. Petrópolis: Vozes, 2002.

BERGER, P. L.; LUCKMANN, T. A construção da realidade social. ı6. ed. São Paulo: Vozes, I985. BERNARDES, A. et al. Os ruídos encontrados na construção de um modelo democrático e participativo de gestão hospitalar. Ciência \& Saúde Coletiva, Rio de Janeiro, v. I2, n. 4, p. 86I-870, 2007. BRITO, M. J. M. A configuração identitária da enfermeira no contexto das práticas de gestão em hospitais privados de Belo Horizonte. 2004. 393 p. Tese (Doutorado em Administração)-Faculdade de Administração e Ciências Econômicas, Universidade Federal de Minas Gerais, Belo Horizonte, 2004 .

CAPPELLE, M. C. A.; BRITO, M. J. M. Relações de poder no espaço organizacional: o caráter disciplinar das práticas de gestão de pessoas em uma organização de desenvolvimento de software. In: ENCONTRO NACIONAL DA ASSOCIAÇÃO NACIONAL DOS PROGRAMAS DE PÓS-GRADUAÇÃO EM ADMINISTRAÇÃO, 26., 2002, Salvador. Anais... Rio de Janeiro: Anpad, 2002. CAPONI, S. Michel Foucault e a persistência do poder psiquiátrico. Ciência \& Saúde Coletiva, Rio de Janeiro, v. I4, n. I, p. 95-I03, 2009.

CARAPINHEIRO, G. Saberes e poderes no hospital: uma sociologia dos serviços hospitalares. 3. ed. Porto: Edições Afrontamento, I998.

CECÍLIO, L. C. O. A modernização gerencial dos hospitais públicos: o difícil exercício da mudança. Revista de Administração Pública, Rio de Janeiro, v. 3, n. 31, p. 36-47, I997.

Autonomia versus controle dos trabalhadores: a gestão do poder no hospital. Ciência \& Saúde Coletiva, Rio de Janeiro, v. 4, n. 2, p. 3I5-329, I999.

CECÍLIO, L. C. O.; MOREIRA, M. E. Disputa de interesses, mecanismos de controle e conflito: a trama do poder nas organizações de saúde. Revista de Administração Pública, Rio de Janeiro, v. 4, n. 36, p. $587-608,2002$.

CHERUBIN, N. A. Administração hospitalar: fundamentos. São Paulo: Cedas, I999.

CRAMPTON, J. W.; ELDEN, S. (Ed.). Space, knowledge and power: Foucault and geography. Aldershot: Ashagte, 2007.

ENRIQUEZ, E. Os desafios éticos das organizações modernas. RAE, São Paulo, v. 37, n. 2, p. 6-I7, abr./jun. I997.

FARIA, J. H. Tecnologia e processo do trabalho. Curitiba: Editora da UFPR, I997.

FEUERWERKER, L. C. M.; CECÍLIO, L. C. O. O hospital e a formação em saúde. Desafios atuais. Revista Ciência e Saúde Coletiva, Rio de Janeiro, v. I2, n. 4, p. 965-97ı, 2007.

FISCHER, G. N. Espaço, identidade e organização. In: CHANLAT, J.-F. (Coord.). O indivíduo na organização: dimensões esquecidas. São Paulo: Atlas, I994.

FOUCAULT, M. Microfísica do poder. Rio de Janeiro: Graal, I979. Vigiar e punir: nascimento da prisão. Petrópolis: Vozes, I987. O nascimento da clínica. 4. ed. Rio de Janeiro: Forense Universitária, I994. Em defesa da sociedade. São Paulo: Martins Fontes, I999. 
FOUCAULT, M. Estratégia, poder-saber. Ditos e escritos, IV. Rio de Janeiro: Forense Universitária, 2003.

A hermenêutica do sujeito. São Paulo: Martins Fontes, 2004.

GONÇALVES, E. L. Estrutura organizacional do hospital moderno. Revista de Administração de Empresas, São Paulo, v. 38, n. I, p. 80-90, jan./mar. 1998.

GONÇALVES, J. F. G. Foucault, a descontinuidade histórica e a crítica da origem. Revista Aulas, Campinas, n. 3, p. I-2I, 2007. Disponível em: <http://www.unicamp.br/ aulas/o7.htm>. Acesso em: 3I maio 20I0.

GOULART, I. B. (Org.). Temas de psicologia e administração. São Paulo: Casa do Psicólogo, 2006.

HALL, R. H. Organizações, estrutura e processos. Rio de Janeiro: Prentice Hall do Brasil, I984.

LARSON, M. S. The rise of professionalism: a sociological analysis. Berkeley: University of California

Press, I977.

LEBRUN, G. O que é poder. São Paulo: Brasiliense, i984.

LUNARDI, V. L. et al. Nursing ethics and its relation with power and work organization. Rev. Latino-am Enfermagem, v. I5, n. 3, p. 493-497, 2007.

LUZ, M. T. Instituições médicas no Brasil: instituição e estratégia de hegemonia. 3. ed. Rio de Janeiro: Graal, I986.

MAY, T. Foucault now? Foucault Studies, Denmark, n. 3, p. 65-76, Nov. 2005.

MINAYO, M. C. S. O desafio do conhecimento: pesquisa qualitativa em saúde. 7. ed. São Paulo: Hucitec, 2000.

MINISTÉRIO DA SAÚDE. Portaria $n^{\circ}$ 2.225/GM, de 05 de dezembro de 2002. Diário Oficial da União, 236, Seção I. Disponível em: <http://dtr200I.saude.gov.br/sas/PORTARIAS/port2002/ gm-2225.htm>. Acesso em: I3 abril 2007.

SAINSAULIEU, R. L'identite au travail. Paris: Presses de la Fondation Nationale des Sciences Politiques, I977.

STAUB, I. D.; BULGACOV, S. Territorialidade, competição e papéis gerenciais: um estudo de agências bancárias de Curitiba. In: ENCONTRO NACIONAL DA ASSOCIAÇÃO NACIONAL DOS PROGRAMAS DE PÓS-GRADUAÇÃO EM ADMINISTRAÇÃO, 24., 2000, Florianópolis. Anais... Rio de Janeiro: Anpad, 2000.

TURNER, J. H. Medical power and social knowledge. London: Sage, I987.

VERGARA, S. C. Projetos e relatórios de pesquisa em administração. São Paulo: Atlas, 2003.

ZAGONEL, I. P. S. Exercício do poder diante da complexidade das relações no espaço médicohospitalar e de enfermagem. Cogitare Enfermagem, Curitiba, v. I, n. 2, p. 75-80, I996. 